Artigo Original

\title{
A repercussão de um diagnóstico de síndrome de Down no cotidiano familiar: perspectiva da mãe*
}

\author{
The impact of a Down Syndrome diagnosis on the family dynamic: mother's perspective \\ La repercusión de un diagnóstico de Sindrome de Down en el cotidiano familiar: perspectiva de la madre
}

\author{
Regina Cátia Sunelaitis ${ }^{1}$, Débora Cristina Arruda², Sonia Silva Marcom
}

\begin{abstract}
RESUMO
Objetivos: Identificar como a mãe percebe o processo de revelação do diagnóstico de Síndrome de Down (SD) e as repercussões disto no cotidiano familiar, o conhecimento sobre a SD e as expectativas em relação ao futuro do filho. Métodos: Estudo descritivo de natureza qualitativa. Os informantes foram três mães de crianças menores de um ano que estiveram internadas na Unidade de Terapia Intensiva pediátrica do Hospital Universitário da Universidade Estadual de Maringá nos anos de 2004 e 2005. Resultados: Os dados revelaram que às vezes este diagnóstico é informado em circunstâncias e momentos inadequados, que as mães conhecem pouco sobre a SD e que quando os problemas de saúde são muitos, suas expectativas se restringem a melhoria e avanços em curto prazo. Conclusão: O desconhecimento, as reações e atitudes das famílias, como, por exemplo, esconder o diagnóstico da família ampliada e até mesmo do pai, constituem indicativos da necessidade de apoio profissional a essas mães/ famílias.
\end{abstract}

Descritores: Família; Síndrome de Down; Relações familiares

\begin{abstract}
Objectives: To describe mothers' perception of the information process of the diagnosis of Down Syndrome and its impact on the family dynamic, and to describe mothers' knowledge of Down Syndrome and expectations regarding their child's future. Methods: This was a qualitative descriptive study. The sample consisted of three mothers of children under 12 months years old who were in-patients in a Pediatric Intensive Care Unit of a University Hospital in 2004 and 2005. Results: The findings suggested that sometimes the information process of the diagnosis of Down syndrome is inappropriate, mothers lack knowledge of the Down syndrome, and mothers' expectations regarding their child's future are focused on short term progresses and improvements. Conclusio: Lack of knowledge and uncertainty of behaviors and attitudes of family members regarding the diagnosis of Down syndrome lead mothers to hide the diagnosis from extended family members and in many instances even from the father. These suggest the need of professional support for the mothers and their family.
\end{abstract}

Keywords: Family; Down Syndrome; Family relations; Mother-child relations; Activities of daily living

\section{RESUMEN}

Objetivos: Identificar cómo percibe la madre el proceso de revelación del diagnóstico de Síndrome de Down (SD) y las repercusiones de éste en el cotidiano familiar, el conocimiento sobre el Síndrome de Down y las expectativas en relación al futuro del hijo. Métodos: Estudio descriptivo de naturaleza cualitativa. Los informantes fueron tres madres de niños menores de un año que estuvieron internados en la Unidad de Cuidados Intensivos pediátrica del Hospital Universitario de la Universidade Estadual de Maringá en los años 2004 y 2005. Resultados: Los datos revelaron que a veces este diagnóstico es informado en circunstancias y momentos inadecuados, que las madres conocen poco sobre el Síndrome de Down y que en cuanto a los problemas de salud son muchos, sus expectativas se restringen a la mejoría y avances a corto plazo. Conclusion: El desconocimiento, las reacciones y actitudes de las familias, como, por ejemplo, esconder el diagnóstico a la familia ampliada y hasta al mismo padre, constituyen indicativos de la necesidad de apoyo profesional a esas madres/familias.

Descriptores: Familia; Síndrome de Down/Relaciones familiares. Relaciones madre-hijo; Actividades cotidianas

\footnotetext{
* Trabalho realizado na Unidade de Terapia Intensiva do Hospital Universitário da cidade de Maringá - PR.

${ }^{1}$ Enfermeira do Hospital e Maternidade São Marcos- São Paulo (SP), Brasil..

${ }^{2}$ Mestre, Enferneira do Serviço de Pediatria do Hospital Universitário de Maringá. Mestre em Ciências da Saúde pela Universidade Estadual de Maringá -UEM-Maringá (PR), Brasil.

${ }^{3}$ Doutora,. Professora dos Cursos de Mestrado em Enfermagem e em Ciências da Saúde na Universidade Estadual de Maringá - UEM- Maringá (PR), Brasil..
} 


\section{INTRODUÇÃO}

A família constitui um conjunto organizado de pessoas que se relacionam e interagem, cada um de seus membros exercendo um papel específico, determinado por questões culturais e pelas necessidades individuais e do grupo ${ }^{(1)}$. Qualquer alteração ou mudança num dos membros pode repercutir em todos os demais. É por essa razão que o comprometimento da saúde dos membros pode causar um estado de crise que desorganiza a estrutura familiar.

Os efeitos sobre a estrutura familiar dependem do membro acometido, do tempo de permanência do agravo e, ainda, de sua gravidade. A doença crônico-degenerativa, em especial a de uma criança, requer da famillia maior tempo e dedicação para o cuidado e, dos profissionais de saúde, maior empenho no sentido de envolver e, ao mesmo tempo, voltar suas ações para a unidade familiar, com vista a fortalecê-la e instrumentalizá-la adequadamente para o desempenho eficaz de suas funções junto a todos os seus membros e, de maneira particular, junto àqueles dependentes de cuidados.

A criança, por ainda encontrar-se em fase de crescimento e desenvolvimento, depende de um cuidador, pois necessita de estímulos, atenção, carinho, compreensão e proteção ${ }^{(2)}$. Por esta razão, a família é tão importante nesse período, mais ainda nos casos de crianças com necessidades especiais, como as portadoras da Síndrome de Down (SD).

Um aspecto importante que envolve esta condição é o desconhecimento ainda existente na população em geral sobre esta síndrome. As pessoas ouvem falar pouco sobre a mesma e diante de um caso na família, sentem-se inseguras e desamparadas. Por essa razão, os profissionais de saúde possuem um papel muito importante junto a essas famílias e suas ações devem ser no sentido de informar e prestar esclarecimentos, como também estimular o vínculo com a criança.

Embora os pais sempre temam a possibilidade de uma má formação, o filho esperado e imaginado é sempre saudável e "lindo". Porém, nos casos em que o filho real difere do imaginário, as respostas de negação ou de aceitação se refletirão no vínculo que é estabelecido e, por conseguinte, nos cuidados dispensados ao filho, bem como no seu crescimento e desenvolvimento ${ }^{(3)}$. Isso porque, quanto melhor forem atendidas as necessidades básicas da criança de afeto e carinho, mais positivas serão as respostas apresentadas de adaptação e desenvolvimento. Não basta cuidar e atender às necessidades fisiológicas: é preciso falar, tocar, acariciar e estimular, e isso tende a acontecer de forma mais natural quando existe vínculo.

Diante do exposto e do entendimento de que a criança hospitalizada deve ser vista sempre à luz de sua constelação familiar, e não isoladamente, e que a meta do cuidado à criança deve estar sempre focada na família, a ocorrência, relativamente freqüente, de internação de crianças com SD em nosso local de trabalho, despertou-nos o interesse em desenvolver o presente estudo, com o objetivo de identificar como a mãe percebe o processo de revelação do diagnóstico de Síndrome de Down e as repercussões desta realidade no cotidiano familiar, o conhecimento sobre a Síndrome e as expectativas relacionadas com a vida futura do filho.

Esperamos que os resultados desencadeiem reflexões de modo a favorecer uma atuação profissional que ultrapasse as barreiras do cuidado clínico e priorize o favorecimento e fortalecimento da tríade mãe-filho-pai.

\section{MÉTODOS}

O estudo é descritivo, de natureza qualitativa, e foi desenvolvido na cidade de Maringá - PR, junto a três famílias, localizadas a partir do levantamento das internações de crianças portadoras de SD ocorridas nos anos de 2004 e 2005 na Unidade de Terapia Intensiva Pediátrica (UTIP) de um hospital-escola. Esse hospital é público e constitui referência para alta complexidade do Sistema Único de Saúde (SUS) no âmbito da $15^{\mathrm{a}}$ Regional de Saúde do Paraná.

Os dados foram coletados no mês de dezembro de 2005, por meio de entrevista semi-estruturada. Oinstrumento utilizado na coleta de dados foi um roteiro constituído de duas partes, a primeira contendo dados de caracterização socioeconômica da familia, e a segunda, dados relacionados com a experiência vivida por ocasião do conhecimento do diagnóstico de SD, mais especificamente com o modo como o diagnóstico foi informado e as reações decorrentes, o conhecimento sobre $\mathrm{SD}$ e expectativas relacionadas ao futuro da criança.

No período investigado estiveram internadas na UTIP cinco crianças, mas só três residiam no município e foram selecionadas para o estudo. Destas três crianças, duas estavam internadas por ocasião da coleta de dados, sendo que uma delas estava internada desde o nascimento e a outra havia sido internada pela segunda vez na UTI, o que despertou o interesse em realizar o estudo. As entrevistas foram previamente agendadas. Nas famílias B e C foram realizadas no domicilio, e na família $A$, por solicitação da informante, realizou-se em sala reservada no próprio hospital, após o horário de visita na UTIP. Tendo em vista maior interação pesquisador-pesquisado, após autorização expressa, as entrevistas foram gravadas e tiveram a duração média de 90 minutos.

Para efeitos de coleta de dados, as famílias estiveram representadas por mulheres/mães, em função de seu papel de cuidador, tanto em situações de saúde quanto de doença, e também porque, na maioria dos estudos realizados com famillias, especialmente quando o foco é a criança, a mãe tem sido a informante principal, pois as mulheres são identificadas como porta-vozes da vida privada, ou seja, da vida em familia(4).

Para a análise dos dados, adotou-se o referencial de análise de conteúdo do tipo temática( ${ }^{(0)}$, a qual envolve um conjunto de técnicas de análise de comunicação visando obter, por procedimentos sistemáticos e objetivos, a descrição do conteúdo das mensagens. Assim, após leitura e escuta flutuante realizada pelos autores, os dados foram 
refletidos, para escanção e o reagrupamento em sistema de categorias.

O estudo obedeceu ao preconizado pela Resolução n. ${ }^{\circ}$ 196/96 do Ministério da Saúde, tendo sido aprovado pelo Comitê de Ética em Pesquisa com Seres Humanos do Centro Universitário de Maringá - CESUMAR, e as três mães assinaram o Termo de Consentimento Livre e Esclarecido.

\section{RESULTADOS}

As três crianças tinham menos de um ano quando do internamento na UTI. A criança da família A tinha cinco meses e estava internada desde o nascimento; as outras duas necessitaram de internamento por problemas respiratórios. As três famílias encontravam-se em uma importante fase do seu ciclo de desenvolvimento, ou seja, a de aquisição(5); são do tipo nuclear e podem ser consideradas pequenas, pois têm, no máximo, dois (FB e FC) ou três filhos (FA).

Os pais tinham idade entre 26 e 35 anos, eram alfabetizados, com, no mínimo, o ensino fundamental completo (só o pai da FC iniciou um curso superior). Duas mães, após o nascimento da criança, deixaram de trabalhar para cuidar do filho. No caso da mãe que continuou trabalhando fora de casa, é importante ressaltar que a criança nunca chegou a ir para casa, pois sempre esteve internada na UTI (neonatal e pediátrica), e que a atividade laboral da mãe é desenvolvida em empresa familiar, o que permite flexibilidade no horário para as visitas. Os pais desenvolviam atividades autônomas e a renda das famílias A e B era de quatro salários-mínimos e a da $\mathrm{C}$ era de um salário-mínimo.

Para facilitar a interpretação e discussão dos dados coletados, traduzimos as questões do instrumento utilizado nas entrevistas em tópicos seqüenciais.

A percepção da mãe sobre a revelação do diagnóstico da Síndrome de Down

Nas três famílias, o diagnóstico ou a suspeita foram comunicados à mãe individualmente e logo após o nascimento da criança, desencadeando tensão, angústia e estresse. As mães revelaram ressentir-se do fato de não terem sido preparadas para o nascimento de um filho com SD. Relataram ter realizado adequadamente o pré-natal, com acesso a recursos como ultra-sonografia. Acreditam que este exame poderia ter antecipado o diagnóstico e que os médicos deveriam ter preparado a família para receber esse filho.

Para a FA e a FC, a abordagem foi singular e subjetiva, e feita num momento em que o diagnóstico era só uma possibilidade.

A médica estava suspeitando, ela falou para nós que ele não tinha todas as características de Down... ai chamaram vários pediatras... eles ficaram em dúvida... demorou uns quatro meses para sair o resultado, ele fez o cariótipo duas vezes, ai que a gente ficon sabendo... (FC)

Em contrapartida, no relato da mãe da família B o diagnóstico foi relatado na hora do nascimento e quando a mãe estava sozinha.

O diagnóstico chegou para mim "na lata".. Foi horrivel. O pediatra falou na hora que ela nasceu, meu marido não estava. Ele perguntou se meu marido era japonês, en disse que não, ele disse que minha filha tinha um problema e que amanhã a gente conversava. No outro dia, ele disse que achava que minha filha tinha SD e que ia pedir o cariótipo. (FB)

A revelação deste diagnóstico normalmente desencadeia sentimentos de decepção, choque, revolta e outros:

Eu nem sei explicar como me senti, porque é uma coisa que ninguém espera. A gente espera nove meses, pensando ser uma criança perfeita, e eu falarpara vocé que a gente espera uma criansa com SD ou alguém com problema, é mentira, eu demorei bastante para me recuperar. (FB)

Eu a desejei tanto, sabe, desde o primeiro dia, en a desejei demais. Eram planos e planos, nomes, tudo, roupas, brinquedos... Não via a hora de ela nascer. Só que foi muita coisa, para mim que esperava tanto, tanto, foi um choque, um atrás do outro. Sabe o que é um bebê seu nascer e a enfermeira olhar para você e falar assim, você vin o seu bebê, e perguntou: ela éperfeita, en falei não... (FA)

\section{Reação da mãe diante da confirmação da Síndrome de Down}

Em seus relatos as mães revelaram que, num primeiro momento, esconderam o diagnóstico de alguns membros da família ampliada, e até do pai da criança,

Esse problema de Down me afetou, afeton o men marido... A família não sabe, nós não quisemos comentar pra família, porque a gente sofre, vamos sofrer nós dois agora, né. Eu não quero pena de ninguém... (FA)

Eu contei para o meu marido só depois que tive certera, 45 dias depois. (FB)

Revelaram, ainda, o sofrimento por medo de a criança ficar doente e ser vítima de preconceito:

É claro que, quando chega assim para você e fala que teu filho é Down, você leva um choque. Eu sofri muito por medo que ele ficasse doente, é o medo de ele vir a sofrer preconceito, porque eu sei que, apesar de ter bastante esclarecimento, hoje em dia, a televisão esclarece bastante, as crianças trabalham e tudo, mas ninguém olha para uma criança assim e vê uma pessoa normal. (FC)

Além disso sentimentos de negação e punição:

Foi um vazio total, eu não aceitei, como acho que muita gente não aceita. Men marido já aceitava... Ele gostava, achava bonito uma criança com problema de Down. É algo que você pergunta: por que comigo, por que minha filha? (FA) 
E, também, que precisam de algum tempo para se conscientizar de que tudo é real e sem volta:

Foi um choque... Mas eu, pra te falar a verdade, para falar para o meu marido, demorou uma semana. (FA)

Inclusive, revelaram que o fato de já ter convivido com outras crianças com SD não chega a minimizar o sofrimento quando se trata de um filho, podendo até piorar:

Eu trabalbei numa fundação que eu tinha 120 crianças que en cuidava e 15 delas eram Down, então você tem uma convivência; mas não é a mesma coisa que ter um filho com SD, né, dai que você tem a noção do que é. (FB).

\section{Lacunas no conhecimento da mãe sobre a} Síndrome de Down

Ao serem questionadas sobre seu conhecimento sobre a $\mathrm{SD}$, as mães manifestaram que, mesmo já tendo passado algum tempo (a criança mais nova já tinha cinco meses), ainda sabiam muito pouco sobre $\mathrm{SD}$ e gostariam de saber mais.

O que a gente sabe assim, na teoria, é que não é uma doença, e que vai demorar um pouquinho mais, mas ele vai ter uma vida normal. Tem as limitaçoess, é claro, e as doenças que vêm junto, que épior... que depende muito da familia para a criança desenvolver; quanto mais ele fica parado, mais ele vai demorar para desenvolver, para aprender coisas. (FC)

Revelaram, ainda, que veículos de comunicação de massa, como a televisão, por exemplo, têm-nas auxiliado na compreensão do problema de saúde do filho.

Nada, o que en sei é o que en ouco por televisão... Mas en gostaria de saber o que ela tem de diferente, o que poderá acontecer na vida dela de diferente em relação a uma criança normal... (FA)

Expectativas da mãe em relação ao futuro do filho

Em relação ao futuro, observou-se que as duas mães que já convivem diuturnamente com a criança apresentam expectativas diversas. A mãe da família B, apesar de temerosa e insegura, visto que a filha estava internada na UTIP pela segunda vez em menos de um ano, demonstrou possuir expectativas positivas em relação o seu desenvolvimento e futuro:

Eu espero que ela consiga sair dessa alergia, porque, fora isso, ela vai ser uma criança praticamente normal, porque é "Graças a Deus" que a SD dela é leve, não é uma coisa assim mais complicada. Ela é, assim, bastante inteligente, o que você ensina para ela, é, assim, coisa rápida, né. Ela demorou para começar a sentar, aí ela fazia aquele esforro... Ela insiste naquilo que ela quer faz̧er.. Ela é uma criança bem ativa... Depois de tempo que en vim saber que quem é Down demora mais assim na parte motora... A gente faz o possivel para ela poder melhorar a parte clínica dela. (FB)

Já a mãe da família C preferia, como ela mesma diz, "viver um dia de cada vez", ou seja, sem criar tantas expectativas.

Sinceramente, eu nem penso, assim, como ele vai estar daqui a 10 anos, porque é melhor viver um dia de cada vez... Eupenso assim: hoje ele está bem "Gracas a Deus", eu não penso daqui a 2, 3, 4 anos, não penso se ele vai estar andando, se ele vai estar falando. Eu sei que ele pode vir a falar, a andar, mas eu não penso quando isso vai acontecer... Como eu não conbeço outro bebê com SD, então eu não sei se o desenvolvimento dele está muito atrasado em relação aos outros... Não é que eu não tenho expectativa, eu não penso, eu não me preocupo muito como ele vai estar. (FC)

Não obstante, a mãe da família $A$ revelou toda a sua descrença na possibilidade de sobrevivência da filha, fato que veio a se confirmar mais tarde, já que a criança faleceu aos sete meses sem nunca ter saído da UTI.

Para falar a verdade, eu não sei..., não sei se ela vai conseguir sair daqui viva. Toda vez que vai melhorando, tem uma recaída, então en não sei como vai ser, não vejo muita saída... (FA)

\section{DISCUSSÃO}

Observamos, nos relatos, que existem diferentes maneiras de os profissionais comunicarem aos pais de um recém-nascido o diagnóstico de uma doença congênita como a SD. A forma como a abordagem foi feita com a mãe da FC foi bem aceita por esta, que valorizou o fato de o médico não esconder a suspeita, informá-la sobre o significado da doença e das possibilidades para confirmação do diagnóstico. O que se pôde perceber é que o profissional, ao mesmo tempo em que preparava a família para o recebimento de um diagnóstico indesejável, também demonstrou interesse em esclarecer o fato, e isso foi percebido de forma muito positiva pela família.

Em contrapartida, no relato da mãe da família B é possível perceber que a forma como este diagnóstico foi comunicado resultou numa percepção muito ruim sobre esta experiência. Os fatos que marcaram essa mãe foram: o caso ter-lhe sido comunicado logo após o parto e em momento em que ela estava sozinha e, ainda, o médico fazer referência a um problema sem especificar qual. A associação de todos estes aspectos favoreceu a exacerbação da angústia e do sofrimento dessa mãe, de tal forma que ela não se sentiu segura para buscar ajuda, nem mesmo com o pai da criança e, por esta razão, só após 45 dias teve coragem de falar com ele sobre o problema.

Tomar conhecimento do diagnóstico de uma condição crônica e com tantas limitações como a SD não é fácil para 
os pais, em especial para as mães, que se mostram decepcionadas, ao mesmo tempo em que lutam para elaborar a perda do filho imaginário.

As mães revelaram ter sentido necessidade de apoio no momento em que tomaram conhecimento do diagnóstico, eisto é compreensível, pois a "chegada" de um filho encontrase entre os acontecimentos significativos que marcam uma importante mudança de ciclo no desenvolvimento familiar ${ }^{(5)}$. É um acontecimento que, embora considerado normal, demanda do casal e da família uma série de mecanismos de ajuste para o enfrentamento e incorporação da nova situação, provocando alterações na dinâmica familiar ${ }^{(5)}$. Nos casos em que ocorre o nascimento de um filho com algum problema de saúde ou necessidade especial, isto é particularmente exacerbado, afetando toda a dinâmica familiar.

Por esta razão, o momento e a forma como o diagnóstico de algumas condições, como a SD, é comunicado à família, constitui um aspecto importante para o processo de adaptação familiar. Alguns estudos têm apontado que o diagnóstico da SD tem sido revelado aos pais de forma incorreta e em momentos inoportunos, destacando os problemas que isto pode trazer no estabelecimento do vínculo com a criança e na superação do luto ${ }^{(7)}$. Por exemplo, os pais percebem que muitos dos problemas e medos que experienciaram e experienciam são decorrentes de informações tardias, erradas e incompletas ${ }^{(8)}$.

Sendo assim, é de supor que quanto antes os pais tomarem contato com o diagnóstico, provavelmente mais os bebês portadores de SD serão beneficiados. Entretanto isto não é válido para todos, já que cada indivíduo tem uma maneira própria de reagir aos fatos e eventos que marcam a vida. Por esta razão, cada caso deve ser considerado em particular. Se o conhecimento do diagnóstico ocorre ainda durante a gestação, é de supor que os pais terão maior oportunidade de se preparar para a aceitação da condição da criança, porém não podemos deixar de considerar que por um bom tempo, ou seja, até o nascimento, eles também irão conviver com a angústia do desconhecido e a preocupação quanto ao grau de comprometimento $^{(9)}$.

Se o diagnóstico só é feito após o nascimento, o momento de comunicá-lo aos pais deve levar em consideração suas necessidades e também as do bebê. É importante permitir que os pais vivenciem os primeiros contatos com o recém-nascido e tenham a oportunidade de iniciar a formação do vínculo afetivo, o qual não se dá apenas pelo nascimento. Este é um processo gradual, precisa de um tempo, sendo a amamentação um fator importante para que a mãe e o bebê iniciem este processo. Desta forma, acredita-se que seria melhor, para os pais e também para os bebês, que o diagnóstico fosse dado pelo menos $48 \mathrm{~h}$ após o parto ${ }^{(7)}$. Alguns estudos identificaram que as mães consideram ideal ser informadas entre o $5^{\circ}$ e $30^{\circ}$ dias após o nascimento do bebê $\hat{e}^{(10)}$ - portanto, nunca no momento do parto, como ocorreu para a mãe da FC.

A circunstância em que o diagnóstico é comunicado é relevante. Estudos realizados junto a pais de filhos especiais têm identificado que eles se ressentem muito da forma como a notícia foi dada ${ }^{(8-11)}$. Por exemplo, sempre que for possível, é importante dar a notícia quando os cônjuges estiverem juntos, pois os pais relatam angústia e sofrimento muito grande quando a noticia é dada separadamente e, com freqüência, quem recebeu primeiro a notícia fica, por um tempo, sem coragem de contar ao outro ${ }^{(8)}$. Além disso, depoimentos de mães relatando como souberam do diagnóstico de SD revelam com muita freqüência a postura negativa de alguns profissionais nesse momento ${ }^{8-}$ 9), caracterizada pelo fato de não fornecerem as explicações necessárias, deixarem as pessoas angustiadas para o enfrentamento da nova situação, não saberem transmitir amparo e segurança nem estarem preparados, ou seja, não possuírem conhecimento que lhes permita explicitar informações de forma adequada às pessoas competentes $^{(8)}$.

Com relação a este aspecto, mister se faz esclarecer que não existe uma receita a ser seguida, mas sim, aspectos a serem considerados com vistas a amenizar o choque que sempre vai existir ao se tomar conhecimento de tal fato. É preciso, por exemplo, ter sensibilidade e ética para reconhecer que cada familia tem uma história de vida única, e por isto, suas necessidades também são únicas. Por esta razão é importante que o profissional que vai dar a notícia esteja preparado para tal: deve estar imbuído dos sentimentos que a notícia vai desencadear e ter respeito e empatia com as pessoas que vão receber o diagnóstico. Neste contexto, necessário se faz tomar cuidado, até mesmo com o tom de voz, com a expressão, com o uso das palavras, com o local e o momento para dar a notícia ${ }^{(8)}$. Sua postura também é importante, pois se fizer esta comunicação de forma pessimista, carregada de sentimentos e fatos negativos ou se simplesmente jogar um monte de informações, sem dar tempo para a família elaborá-las, fazer questionamentos, chorar e se revoltar, ao invés de ajudar, vai colaborar para o agravamento da fase do luto, que naturalmente ocorrerá( ${ }^{(12)}$.

Além disso, o profissional deve estar atualizado no que diz respeito à síndrome, de forma a ter condições de fornecer informações suficientes para aquela etapa da vida da criança, sem deixar de enfatizar as possibilidades de desenvolvimento afetivo, social e cognitivo destas crianças quando estimuladas adequadamente, e também de responder a todas as questões apresentadas pela família ${ }^{(9)}$.

Destarte, informar correta e claramente os pais sobre a SD, de forma humanizada, com respeito, sem iludir, tampouco omitir como provavelmente será o desenvolvimento da criança é primordial para os pais. $\mathrm{O}$ 
profissional precisa ter sensibilidade para perceber o que eles realmente necessitam, desejam e querem saber naquele momento, sem deixar de considerar que a angústia, a ansiedade e até mesmo a não-aceitação daquele bebê podem aflorar.

Outro papel importante dos profissionais junto a essas famílias diz respeito ao preparo para a alta, já que levar o filho para casa não é fácil para os pais. Eles têm medo por não saber como cuidar de seu filho e a quem recorrer em situações desconhecidas. Nesta ocasião devem ser ressaltados os recursos da comunidade disponíveis, os possíveis locais onde possam buscar apoio diante de intercorrências e subsídios que os auxiliem nessa caminhada.

No que diz respeito às reações após o diagnóstico de SD, observou-se que as três mães, num primeiro momento, tentaram negar este diagnóstico. Isso foi identificado a partir do relato de algumas atitudes, como, por exemplo, a de esconder o diagnóstico de alguns membros da família ampliada e até mesmo do esposo. É importante considerar que o fato de a mãe não contar para outras pessoas pode indicar que ela ainda não se sente fortalecida para falar sobre esse assunto.

A adaptação do filho idealizado para o real é um processo que demanda tempo e é vivenciada de forma conflituosa, podendo ser considerada uma vivência marcante para todos os elementos da família. No entanto, embora o choque diante do diagnóstico de SD seja inevitável, em especial para a mãe, normalmente a maioria das famílias supera a crise e atinge um equilíbrio. Por esta razão, o fato de duas mães terem optado por não compartilhar, durante algum tempo, o conhecimento do diagnóstico, até mesmo com o pai da criança, fez com que elas se privassem do apoio que poderiam receber naquele momento difícil de suas vidas ${ }^{(13)}$, além de retardar o alcance do equilíbrio familiar. Mas este, ao que parece, é um tempo que elas precisam.

A ajuda e a mediação de profissionais podem minimizar o impacto, mostrando as possibilidades positivas, e não somente os aspectos negativos. Quanto mais adequada for a revelação do diagnóstico, menor será a situação de desamparo enfrentada pelos pais ${ }^{(12)}$. Com relação a este aspecto é importante considerar que, embora normalmente caiba ao médico comunicar aos pais o diagnóstico, os profissionais de enfermagem são os que permanecem 24 horas por dia nos hospitais e, por isso, os que terão maior contato com a puérpera e seu bebê. Por esta razão, esse profissional tem um papel muito importante junto aos membros de uma família que vivencia tal situação, devendo, pois, estar preparado para cuidar da família e em especial da mãe, após a notícia. De que forma? Estando junto/ perto, apoiando, ouvindo, tocando, permitindo o choro e a revolta. Isto tudo porque, segundo os pais, muitas perguntas deixam de ser feitas pelo choque da informação ou por não saberem nem ao menos que se trata da síndrome; atônitos, não sabem o que e como perguntar. Depois do primeiro impacto, quando começam a refletir sobre as informações recebidas, surgem vários questionamentos e normalmente elas não têm com quem conversar, o que lhes causa muito sofrimento.

As primeiras experiências de interação dos pais e familiares com a criança podem ficar comprometidas pelo impacto produzido na família pela notícia de ter um filho com essa síndrome ${ }^{(3)}$. Por essa razão, é tão importante que pais de filhos sindrômicos recebam, o mais precocemente possível, apoio e incentivo para procurarem as melhores condições de crescimento e desenvolvimento do filho, mediante estímulos físicos, motores e intelectuais. Também não podemos deixar de considerar que as famílias diferem em sua reação diante do nascimento da criança com SD, em função de seu estágio de vida familiar, do papel desempenhado pela criança na configuração familiar, do impacto da notícia, do significado dessa condição para os componentes familiares ${ }^{(14)}$, da personalidade de cada mãe e cada pai, do relacionamento entre eles, de suas experiências e de suas crenças ${ }^{(8)}$. Algumas passam por um período de crise aguda, recuperando-se gradativamente. Outras têm mais dificuldades e desenvolvem uma situação de tristeza crônica $^{(15)}$. Os profissionais precisam estar atentos a esta questão, pois se os membros da família são instáveis ou permanecem abalados, sem conseguir superar a chegada do filho com necessidades especiais e alcançar o tão necessário reequilíbrio, essa criança poderá ter seu crescimento e desenvolvimento prejudicados ${ }^{(9)}$.

Para que a aceitação ocorra, a família terá que se permitir experienciar os diferentes estágios relacionados com as perdas, até atingir o ponto em que as mudanças no ritmo de vida estejam incorporadas e a aceitação da criança e de suas limitações seja alcançada. Normalmente, diante de uma perda, as pessoas passam por vários estágios: choque, negação, raiva, negociação, depressão e organização emocional, com a conseqüente aceitação ${ }^{(9,16-17)}$.

Os dados revelaram que o fato de conhecer e mesmo ter convivido com outras pessoas com o mesmo problema não é capaz, por si só, de facilitar a aceitação desta condição no interior da família, conforme revelado pela mãe da família B. e ao que parece, interfere nesta experiência o medo do preconceito que a criança possa vir a sofrer. Há que se considerar que a preocupação é, aparentemente, relacionada à atitude da sociedade para com a criança. Isso se justifica pelo fato de que cada um de nós têm idéias preconcebidas em relação às pessoas com necessidades especiais, o que influirá em nossas atitudes e interações com elas $^{(3)}$.

Destarte, a reação da família é fruto do contexto em que ela vive, e neste, infelizmente, ainda predomina a falta de conhecimento, a rejeição e o preconceito em relação ao diferente. Assim, o medo da mãe é justificado, pois ainda 
temos um longo caminho a percorrer até que mudanças atitudinais, relacionadas com a inclusão social, sejam a tônica em nosso meio.

Não obstante, um aspecto que interfere sobremaneira no modo de a família lidar com o problema é o conhecimento que ela tem sobre a síndrome. Observou-se que esse conhecimento é limitado, mesmo depois de duas delas já terem convivido diuturnamente com tal condição durante algum tempo, revelando uma falha importante dos profissionais de saúde com estas famílias. Isto é extremamente preocupante, pois a atuação da família junto à criança com SD depende do conhecimento que ela tenha sobre a síndrome e também sobre as possibilidades de tratamento. Este é um problema real. Estudo realizado na cidade de Sobral - CE - identificou que mais da metade das mães / cuidadoras de portadores de SD não conhecia e também não tinha nenhuma informação sobre a síndrome e as necessidades dos portadores ${ }^{(0,18)}$.

Neste estudo, as mães mostraram sentir medo, devido principalmente a não saber como cuidar, o que poderia acontecer com ele, e se o filho iria conseguir fazer o que fazem as crianças ditas normais. Revelaram, portanto, necessidade de alguém que as ajudasse a, aos poucos, compreender, aceitar, ter esperanças e amar seu filho. Isto é muito importante, pois à medida que recebem explicações e informações voltadas para o que realmente querem e necessitam saber, maior compreensão sobre a SD e de como agir diante dela vai sendo construída.

Os pais precisam saber, por exemplo, que ter acesso à tecnologia e a profissionais qualificados é importante, mas não é tudo. A participação ativa e o envolvimento da família no processo de tratamento do filho são de grande valia para o estágio de desenvolvimento que a criança alcançará. Famílias que conseguem manter ligação afetiva estreita e positiva com a criança favorecem um desenvolvimento e crescimento com mais segurança e autonomia ${ }^{(3)}$.

Este é um papel ao qual o profissional de saúde não pode se furtar. Ele deve atuar com o objetivo de fortalecer a família para os enfrentamentos. As famílias dependem, nesse momento, de reconhecimento do problema do filho, de ações facilitadoras para compreender as situações vividas, e quanto mais esclarecidas estiverem, melhor será seu empenho no cuidado do filho ${ }^{(19)}$.

Os pais precisam, por exemplo, ser esclarecidos de que desde os primeiros meses, a criança com $\mathrm{SD}$ tem dificuldades para manter a atenção e estar alerta aos estímulos externos. Em geral, é menos interativa e responde menos aos adultos, mas isso não significa que não seja capaz de desenvolver tal tipo de comportamento. A exploração do ambiente faz parte da construção do mundo da criança, e o conhecimento que ela obtém, dessa maneira formará sua bagagem para se relacionar com o ambiente.

Os primeiros anos de vida de uma criança constituem um período crítico em seu desenvolvimento cognitivo, e o papel da família nesse período é fundamental, principalmente nos casos de crianças com necessidades especiais, visto que seu desenvolvimento não depende só do grau em que são afetadas intelectualmente, mas também de vários outros fatores, sendo o ambiente familiar o principal deles.

Por essa razão, nas crianças com SD, o desenvolvimento da inteligência não depende apenas da alteração genética, mas também das importantes influências e situações capacitadoras do meio em que elas estão inseridas ${ }^{(3)}$. Assim, capacidades cognitivas e motoras, desde que sejam treinadas e façam parte da vida social das crianças com SD, virão a se desenvolver de modo rápido e surpreendente, pois a inteligência não se define, não tem um grau estabelecido: ela se constrói, dependendo do contexto familiar, social e escolar de que a criança participa ${ }^{(9)}$. Tal fato, mais uma vez, ressalta o importante papel dos profissionais de saúde junto a estas famílias, esclarecendo e incentivando a precocidade de estímulos adequados, o que não significa, apenas, acesso a equipamentos e profissionais especializados.

O fato de duas mães terem revelado que não criaram expectativas em relação ao futuro do filho pode representar uma atitude de defesa, mas também pode estar relacionado ao desconhecimento sobre as possibilidades de desenvolvimento da criança, o que as leva a preferir "viver um dia de cada vez". Os profissionais, no entanto, devem ficar atentos para perceber até que ponto isto compromete as possibilidades da criança.

O desconhecimento sobre as condições ideais relacionadas ao desenvolvimento infantil é notado, por exemplo, quando a mãe relata não saber se o filho está em condição de atraso em relação a outras crianças. Se a falta de informação e orientação constitui fator que dificulta a aceitação e a atuação da família diante da SD, ao reconhecermos esta condição nas famílias em estudo, vislumbramos quanto nossa atuação junto a essas famílias está sendo falha.

\section{CONCLUSÃO}

As mães em estudo revelaram o impacto sofrido ao receberem o diagnóstico de SD; porém, enquanto profissionais de saúde, chamou-nos a atenção o fato de este diagnóstico ter sido dado em condições e momentos inapropriados. Deveria ter sido comunicado à família, e não somente à mãe, que revelou carregar sozinha, por um tempo, o peso desse fato. Além disso, esta comunicação deveria ser planejada, tendo em vista o apoio, o esclarecimento de dúvidas e a melhor compreensão possível por parte da família, a respeito da situação.

A partir da chegada à família de uma criança com SD, esta se torna o centro de sentimentos, pensamentos, dúvidas, incertezas e, principalmente, de medo do desconhecimento, pelo desconhecimento do que a SD pode provocar de malefícios para a criança, e do preconceito que ela possa vir a sofrer; preconceito este vivenciado também pelos pais, 
que muitas vezes optam por não revelar o diagnóstico nem sequer para a família ampliada.

Não obstante, a família, não pode se privar do apoio de sua rede social, a qual poderá colaborar no cuidado à criança e em sua própria reestruturação. Isto porque a estruturação psicológica da família e/ou uma rede de suporte atuante constituem a melhor ferramenta para o cuidado ao filho com necessidades especiais.

Os profissionais de saúde, por sua vez, têm um papel importante a desempenhar: junto a estas familias: de um lado, precisam ajudá-las a reconhecer suas forças e potencialidades, bem como suas fragilidades e necessidades; e de outro, ao reconhecerem o importante papel da família junto a essas crianças, precisam efetivamente estar junto com elas, apoiando-as e instrumentalizando-as para que possam, respeitando seus limites e dificuldades, cuidar de seu membro familiar da melhor maneira possível.

Isto significa fornecer informações de forma gradativa e constante, até que a família esteja suficientemente esclarecida e pronta para ajudarem esse filho. A família não deve ser "enganada", e por isto, à medida que as demandas chegam, as informações não devem ser omitidas, mas é preciso respeitar o ritmo, a individualidade e o tempo de cada família, já que normalmente não estão preparadas para saber tudo de uma só vez.

Assim, em suas interações com as famílias, e em especial com a puérpera, o profissional precisa desenvolver a capacidade de ouvi-las sobre seus medos, dúvidas e necessidades e, acima de tudo, utilizar-se de termos simples e adequados e, ainda, estar atento para a necessidade de sempre checar seu entendimento sobre as informações oferecidas.

Mister se faz, considerar que estar junto com a família e apoiá-la não significa saber reconhecer os momentos oportunos apenas para acrescentar informações, mas também para promover interações; ou seja, é preciso ter em mente que as condições e necessidades das famílias devem sobrepor-se aos protocolos estabelecidos. Assim, se por um lado, faz-se necessário estimular e promover o estabelecimento de vínculos entre a família e a criança, para o bem-estar de todos na família, e principalmente para o desenvolvimento da criança, por outro, é preciso que se considere que isto não pode ser imposto, tem que ser conquistado, promovido.

Ao se fazer presente, ao partilhar com a mãe/familia suas inquietudes e sofrimentos, enfim, ao deixá-las perceber que não estão sós no enfrentamento desta difícil situação, sem dúvida o profissional estará contribuindo para a promoção de condições favoráveis ao estabelecimento do vínculo com a criança.

\section{REFERÊNCIAS}

1. Althof CR. Delineando uma abordagem teórica sobre o processo de conviver em familia. In: Elsen I, Marcon SS. Silva MRS. O viver em família e sua interface com a saúde e a doença. 2 a ed. Maringá: Eduem, 2004. p. 29-42.

2. Barbosa ECV, . Humanização nas relações com a família: um desafio para a enfermagem em UTI Pediátrica. Acta Sci Health Sci. 2004; 26(1): 205-212.

3. Voivodic MA; Storer MRS. O cognitivo das crianças com de Down à luz das relações familiares. Psicol Teor Prát. 2002; 4(2):31-40.

4. Marcon SS, Elsen I. Um estudo trigeracional sobre a experiência de famílias ao criarem seus filhos. Ciência Cuidado e Saúde 2002 Set; 1 (1): 111-116.

5. Berthoud CME. Visitando a fase de aquisição. In: Cerveny CMO, Berthoud CME. Visitando a família ao longo do ciclo vital. São Paulo: Casa do Psicólogo; 2002. p. 29-58.

6. Minayo MCS. O desafio do conhecimento: pesquisa qualitativa em saúde. 6a ed. São Paulo: Hucitec; 1995.

7. Vash CL. Enfrentando a deficiência: a manifestação, a psicologia, a reabilitação.São Paulo: Pioneira; 1988.

8. Martins, DA. Cuidando do portador de síndrome de Down e seu significante. Ciênc cuidad saúde. 2002; 1 (1):117-122.

9. Iervolino AS. Estudo das percepções, sentimentos e concepções para entender o luto de familiares de portadores da síndrome de Down da cidade de Sobral - Ceará [tese]. São Paulo: Universidade de São Paulo Faculdade de Saúde Pública; 2005.

10. Mustacchi Z. Síndrome de Down. In: Mustacchi Z, Peres S. Genética baseada em evidências: síndromes e heranças [CD ROM]. São Paulo: Centro Israelita de Assistência ao Menor; 2000.

11. Marcucci M. Ninguém está preparado para ter um filho diferente. In: Moro AF organizador. Abordagem multiprofissional em medicina fetal. São Paulo: Roca; 2003p. 41-62.

12. Silva NLP, Dessen MA. Crianças com Síndrome de Down e suas interações familiares. Psicol Reflex Crit. 2003; 16(3): 503514.

13. Silva SF. Experiências e necessidades de mães após o diagnóstico de deficiência mental do filho [tese]. São Carlos: Universidade Federal de São Carlos; 1988.

14. Ribeiro NRR. A famillia enfrentando a doença grave da criança. In: Elsen I, Marcon SS. Silva MRS. O viver em família e sua interface com a saúde e a doença. 2a ed. Maringá: Eduem, 2004.p. 183-198.

15. Casarin S. Aspectos psicológicos da Síndrome de Down. São Paulo: Memnon, 1999.

16. Amaral LA. Conhecendo a deficiência (em companhia de Hércules). São Paulo: RobEditorial; 1995.

17. Kluber-Ross E. Sobre a morte e o morrer. Trad. Paulo Menezes. 6th ed. São Paulo: Martins Fontes, 1998.

18. Souza, MJ de. Familia-pessoa portadora de síndrome de Down na ótica da mãe: uma contribuição para a prática de cuidar na enfermagem [tese ]. Rio de Janeiro. Universidade Federal do Rio de Janeiro - Escola de Enfermagem Anna Nery; 1999.

19. Ramalhão AB; Dupas G. Vivendo a ambivalência: o significado da visita para os pais de neonatos internados em Unidade de Tratamento Intensivo. Acta Paul Enf, São Paulo 2003; 16(3): $41-50$. 